\section{VIVIENDA VERTICAL SOCIAL EN LA FRONTERA NORTE DE MÉXICO: CRITERIOS PARA UNA DENSIFICACIÓN SUSTENTABLE ${ }^{1}$}

Marisol Rodríguez Sosa², Erick Sánchez Flores ${ }^{3}$ y Gabriel García Moreno ${ }^{4}$

\section{Resumen}

Este artículo presenta un estudio sobre seis conjuntos habitacionales con tipologías de vivienda vertical de interés social construidos en Ciudad Juárez en distintas zonas de la ciudad durante los períodos 1950-1970, 1980 y 1990: FOVISSSTE Burócrata (1956), FOVISSTE Sur (1975), FOVISSSTE Chamizal (1980-84), INFONAVIT Casas Grandes (1980s), INFONAVIT Eco2000 (1992-93), INFONAVIT Solidaridad (1990-93). A partir de un análisis físico espacial desarrollado en dos escalas, la urbano-territorial, asociada a la ubicación en la mancha urbana en suelos aptos para la densificación urbana y la urbana-comunitaria, relativa a los conjuntos habitacionales, en particular a las tipologías de vivienda existentes y el porcentaje

\section{VERTICAL SOCIAL HOUSING ON THE NORTHERN BORDER OF MEXICO: CRITERIA FOR SUSTAINABLE DENSIFICATION ${ }^{1}$}

\author{
Marisol Rodríguez Sosa ${ }^{2}$, Erick Sánchez Flores ${ }^{3}$ \\ y Gabriel García Moreno ${ }^{4}$
}

\section{Abstract}

This paper analyzes six vertical social housing developments built in Ciudad Juárez over three periods-1950s-1970s, 1980s and 1990s: FOVISSTE Burocrata (1956), FOVISSTESur (1975), FOVISSTE Chamizal (1980-1984), INFONAVIT Casas Grandes (1980s), INFONAVIT Eco2000 (19921993) and INFONAVIT Solidaridad (1990-1993.) This research conducts a physical-spatial analysis at two different scales: one, the urban-territorial dimension, which refers to the location of land suitable for urban densification within the urban sprawl, and; two, the urban-community dimension, which is associated with housing developments and the percentage of vacant dwellings. Geostatistical data are included to examine the extent to which 
de viviendas deshabitadas. El estudio integra la modelación de datos geoestadísticos, para evaluar en qué medida estos desarrollos con tipologías de vivienda vertical, presentan o no, tanto por su ubicación como por su diseño urbano, características que favorecen la habitabilidad y la sustentabilidad. Se presenta un conjunto de estrategias que permiten transformar estos desarrollos habitacionales densos en comunidades más equilibradas y adaptadas a las necesidades locales. Se presentan conclusiones sobre criterios de densidad favorables a los conjuntos habitacionales con tipologías de vivienda vertical, buscando ofrecer elementos que permitan que los futuros desarrollos puedan dar lugar a comunidades habitables.

\section{PALABRAS CLAVE: DENSIDAD; VIVIENDA VERTICAL; USOS DE SUELO; HABITABILIDAD; SUSTENTABILIDAD.}

Recibido: 14-11-2018

Aceptado. 14-01-2019

1 Artículo basado en investigación “Densificación y vivienda vertical en zonas de centralidad urbana: estudio de estrategias de desarrollo urbano sustentable para Ciudad Juárez, Chih" 206712, con apoyo del Fondo de Desarrollo Científico y Tecnológico para el Fomento de la Producción y Financiamiento de Vivienda y el Crecimiento del Sector Habitacional CONAVI-CONACYT.

2 México. Departamento de Arquitectura, Instituto de Arquitectura, Diseño y Arte, Universidad Autónoma de Ciudad Juárez, https://orcid.org/0000-00025513-9355. Correo electrónico: marisol.rodriguez@uacj.mx.

3 México. Departamento de Arquitectura, Instituto de Arquitectura, Diseño y Arte, Universidad Autónoma de Ciudad Juárez, https://orcid.org/0000-00017963-1128. Correo electrónico: esanchez@uacj.mx.

4 México. Departamento de Arquitectura, Instituto de Arquitectura, Diseño y Arte, Universidad Autónoma de Ciudad Juárez, https://orcid.org/0000-00023578-1906. Correo electrónico: ggarcia@uacj.mx. these vertical developments favor habitability and sustainability both in location and design terms. This paper also offers a series of strategies intended to transform these dense developments into more balanced communities with the capacity to meet local needs. The final section provides conclusions on density criteria in favor of vertical housing and offers elements that may enable future developments to create inhabitable communities.

KEYWORDS: DENSITY; VERTICAL HOUSING; LAND USE; HABITABILITY; SUSTAINABILITY 


\section{Introducción}

El progresivo aumento del número de personas viviendo en ciudades y de la expansión de la mancha urbana que han experimentado muchas ciudades del mundo desarrollado y en desarrollo en el último siglo, ha ubicado a la sustentabilidad urbana en el centro de la agenda urbana de países, ciudades, instituciones e investigadores. El cuestionamiento esencial que se ha hecho una constante y que compartimos a nivel mundial es: "¿Cómo podemos crear lugares futuros que sean sustentables y habitables?" (Berke, Godschalk, Kaiser, y Rodríguez, 2006). Desde la planificación urbana, la sustentabilidad se entiende como "la capacidad de construir sistemas de uso del suelo que sean balanceados y equilibrados desde el punto de vista ambiental" (Marsh y Grossa, 1996). De este modo, la posibilidad de alcanzar la sustentabilidad está directamente relacionada, tanto a nivel territorial, como a nivel del planteamiento urbano específico de un proyecto, con el uso del suelo, entre otros aspectos. En relación con ello, el manejo de la densidad, es decir, del número de unidades de vivienda por hectárea o unidad de medida, es una de las principales acciones dirigidas hacia la posibilidad de un desarrollo urbano más compacto, ordenado, eficiente y respetuoso, en términos de uso de los recursos naturales y del medioambiente.
Desde el siglo XIX la vivienda social se transformó en uno de los principales problemas urbanos de las grandes urbes de los países líderes del desarrollo industrial. Así, la necesidad de plantear nuevas tipologías multifamiliares en vertical para la vivienda social se convirtió en uno de los temas más controversiales o cuestionados de las políticas de vivienda social en muchos países. Las experiencias y debates del siglo XX dejaron ver su lado positivo así como sus desventajas. Le Corbusier fue uno de los pioneros en postular los edificios verticales de alta densidad como solución de la arquitectura y urbanismo modernos para atender la necesidad del aumento de la densidad poblacional. En el Salón de Otoño de París de 1922 presentó el proyecto de la "ciudad contemporánea" donde se exalta la necesidad de aumentar la densidad del centro de las ciudades y para lograr esto: " $a$ ) rascacielos: 3.000 habitantes por hectárea. b) Lotes con arremetimientos: 300 habitantes por hectárea" (Le Corbusier, 2009). Desde 1929, el problema de la "existencia mínima" o de "la vivienda de subsistencia mínima" (Mumford, 2002), fue el protagonista del CIAM 2, los Congresos Internacionales de Arquitectura Moderna (CIAM) liderados por Le Corbusier. Respondiendo a la demanda europeas de construir viviendas de bajo costo después de la primera guerra mundial, la problemática entonces era encontrar soluciones basadas en la producción 
en serie, la racionalización, la estandarización de especificaciones y de equipamientos colectivos, y "enfocados en las soluciones de diseño para el problema de las altas rentas para personas con ingresos bajos" (Mumford, 2002). Desde ese entonces, los altos costos forzaban la reducción del tamaño de las unidades.

El ejemplo de la Unidad Habitacional de Marsella, en Francia (1951), dejó ver las bondades de una arquitectura habitacional de alta densidad, acompañada de amenidades, equipamientos y una gran calidad arquitectónica que fueron claves en el éxito del proyecto. Contrariamente, el conjunto de edificios Pruitt-Igoe, San Luis, Missouri (1955), demolido veinte años después de su inauguración, fue el manifiesto de los aspectos negativos, la monotonía, el predominio de personas de un mismo grupo económico y étnico, el abandono, la falta de mantenimiento. Su demolición provocó el cuestionamiento de la validez de las soluciones de alta densidad y altura para la vivienda social.

En décadas recientes, la "ciudad compacta" ha vuelto a estar en el centro de las discusiones de la ciudad y el urbanismo sostenible (Hagan, 2015). Sin embargo, aún quedan temas pendientes para la comprensión de la densificación, aún no sabemos responder ¿qué tan compacto es compacto? (Hagan, 2015), ni evaluar ¿qué tan sostenible y habitable es la densidad?
En ese sentido, y partiendo de la posibilidad de estudiar los conjuntos ya construidos, nos cuestionamos: ¿qué criterios, tanto en términos de ubicación como de diseño, pueden dar pautas a una densificación más sostenible?

La densificación y la vivienda vertical han vuelto a estar entre los temas centrales de la política pública actual para atender la demanda de vivienda de interés social en México. La intención de optar por la vivienda vertical surge como solución alternativa a la opción de la vivienda unifamiliar, cuya construcción masiva en los últimos años ha demandado la creación de desarrollos habitacionales de gran extensión horizontal y por consecuencia, una expansión exacerbada de la mancha urbana en muchas ciudades mexicanas. A raíz de esto, la política del Gobierno Federal Mexicano a través del Programa Nacional de Vivienda 2014-2018, se ha enfocado en dirigir los apoyos y subsidios hacia los desarrollos habitacionales cuya ubicación y criterios de densidad promuevan un crecimiento más compacto y sustentable. En particular, la política actual contempla otorgar subsidios para la adquisición de una vivienda nueva o usada por un valor equivalente en pesos mexicanos de hasta $\$ 3,770.29$ USD $^{5}$, de acuerdo con un sistema de puntaje en el que se favorece la ubicación en zonas con concentración de empleo, equipamiento y servicios urbanos, así como con densidades medias-altas

$5 \quad$ Tipo de cambio vigente al 29 de octubre de 2018. 
y con vivienda vertical de tres niveles ("Reglas de operación del programa", 2015). Al favorecer estos factores, la política actual busca que el apoyo federal para la atención al déficit de vivienda de las personas de bajos ingresos se concentre en zonas urbanas ya consolidadas, dando con ello mayor derecho a la ciudad a este sector de la población y contribuyendo al mismo tiempo a que las ciudades mexicanas se encaminen hacia el desarrollo más compacto.

En este contexto, es fundamental abordar el tema de los desarrollos habitacionales densos en Ciudad Juárez, Chihuahua, cuya experiencia reciente ha demostrado que la solución al déficit de vivienda no puede resolverse a través de una única fórmula de construcción de vivienda unifamiliar en zonas con bajos valores del suelo alejadas de la ciudad consolidada. Esta solución ha permitido el acceso a la vivienda a los sectores de menores ingresos, pero ha tenido un impacto negativo directo en el desarrollo urbano de la ciudad. En la mayoría de los casos, los habitantes de esos nuevos desarrollos alejados del área consolidada de la ciudad, han quedado a merced de los transportistas. Lo anterior sin mencionar que gran parte del presupuesto del municipio se ha tenido que dedicar a la expansión y pavimentación de las nuevas vialidades, a la extensión de los servicios urbanos, y a la incorporación posterior de los equipamientos educativos, de salud, sociales, culturales, recreativos y deportivos.

Así, aunque se logra otorgar una vivienda digna, no se logra crear un hábitat adecuado que permita la inserción social de los habitantes, que muchas veces quedan aislados y segregados en ciudades dormitorios de trabajadores, como señalan estudios previos:

A siete años de distancia, tenemos una ciudad segregada, desarticulada y con grandes superficies vacías a su interior. El crecimiento disperso y la cuestionable 'demanda de vivienda' han producido un paisaje en donde los barrios consolidados lucen abandonados. A la par, un alto porcentaje de viviendas emplazadas en los nuevos fraccionamientos ni siquiera han sido habitadas ante la falta de accesibilidad a equipamiento y servicios urbanos (Maycotte y Sánchez, 2010).

Uno de los efectos negativos más alarmantes ha sido la progresiva desaparición del uso de suelo habitacional de las zonas de centralidad urbana, pues tanto en estas como en los corredores urbanos existen muchas manzanas en que se reportan cero vivienda habitada. Muchas de las antiguas residencias se han venido transformando en locales de uso comercial, debido a la rentabilidad para usos comerciales que ofrece la localización sobre avenidas principales de amplia visibilidad por los habitantes en sus recorridos diarios. Estudios previos han confirmado además que, "en Ciudad Juárez se observa una correlación espacial directa entre alta inseguridad urbana y baja densidad poblacional, y, asimismo, una correlación entre baja inseguridad urbana y densidad poblacional mediaalta" (Rodríguez, Morales y Curiel, 2015). Nos encontramos así, con un uso de suelo desequilibrado e ineficiente. De un lado, zonas de centralidad con 
infraestructura y equipamiento pero con poco uso habitacional y, de otro, zonas periféricas carentes de equipamiento y servicios, pero sobresaturadas de vivienda de interés social.

A partir de este escenario, como uno de los objetivos de la investigación se realizó un estudio de los principales conjuntos habitacionales con tipologías de vivienda vertical de interés social que fueron construidos en Ciudad Juárez entre 1956 y 1993, con el propósito de aprender de estos desarrollos y poder identificar criterios que permitan que los futuros conjuntos habitacionales densos puedan dar lugar a comunidades habitables y más sustentables. De los seis conjuntos analizados, tres fueron desarrollados para los beneficiarios de créditos hipotecarios del Fondo de la Vivienda del Instituto de Seguridad y Servicios Sociales de los Trabajadores del Estado (FOVISSSTE), creado en los años 1950s; y tres para los beneficiarios de crédito hipotecario del Instituto del Fondo Nacional de la Vivienda para los Trabajadores (INFONAVIT), creado en 1972, cuyo objetivo era facilitar la adquisición de vivienda por parte de trabajadores de bajos ingresos, a partir de la administración de aportaciones obligatorias por parte de patrones.

En orden cronológico se construyó primero el FOVISSSTE Burócrata en 1956, con 393 habitantes; el FOVISSSTE Sur, construido en 1975 hoy con
1.302 habitantes; el INFONAVIT Casas Grandes de 1980 con 12.334 habitantes; el FOVISSSTE Chamizal construido en 1980-84 con 2.331 habitantes, el INFONAVIT Solidaridad (1990-93) con 4.066 habitantes; y el INFONAVIT Eco2000 (1992-93) con 2.810 habitantes. Estos seis conjuntos fueron construidos en distintos períodos y zonas de la ciudad, pero comparten la presencia de edificios de vivienda vertical de interés social de tres y más niveles, mezclada con unifamiliar, de ahí la importancia que revisten para el análisis. Las políticas de vivienda a las que se asocia la promoción de cada uno de estos desarrollos se detallan en la Tabla 1.

El estudio tiene como objetivo identificar criterios de densificación, en particular desde el estudio de estos conjuntos habitacionales con tipologías de vivienda vertical, considerando el nivel urbanoterritorial asociado a la ubicación en la mancha urbana y su coincidencia o no con zonas aptas para la densificación y el nivel urbano de los conjuntos en sí, para detectar aspectos que promueven o no una densificación más habitable y en ese sentido, más sustentable. El propósito es identificar, desde los casos existentes, estrategias y criterios de diseño urbano de vivienda vertical de interés social, que presenten alternativas equilibradas al reto futuro de promover la densificación y verticalización en el marco del desarrollo urbano sustentable. 


\section{TABLA 1. POLÍTICAS DE VIVIENDA ASOCIADAS A LA PROMOCIÓN DE LOS DESARROLLOS DE VIVIENDA VERTICAL EN CIUDAD JUÁREZ.}

\begin{tabular}{|c|c|c|}
\hline $\begin{array}{l}\text { Desarrollo de } \\
\text { vivienda vertical }\end{array}$ & $\begin{array}{l}\text { Fecha de } \\
\text { construcción }\end{array}$ & Política de vivienda \\
\hline $\begin{array}{l}\text { FOVISSSTE } \\
\text { Burócrata }\end{array}$ & 1956 & $\begin{array}{l}\text { Promovido por la Dirección General de Pensiones Civiles y de Retiro del Instituto } \\
\text { de Seguridad y Servicios Sociales de los Trabajadores del Estado (ISSSTE); debe } \\
\text { considerarse que hasta } 1954 \text { se consolida una política de vivienda nacional orien- } \\
\text { tada a la protección de los intereses de las clases vulnerables con la creación del } \\
\text { Instituto Nacional de Vivienda. }\end{array}$ \\
\hline FOVISSSTE Sur & 1975 & $\begin{array}{l}\text { Promovido durante la primera etapa del Fondo de la Vivienda del Instituto de Segu- } \\
\text { ridad y Servicios Sociales de los Trabajadores del Estado (FOVISSSTE), institución } \\
\text { creada en } 1972 \text { luego de las reformas al artículo } 123 \text { de la Constitución, en el cual } \\
\text { se establece la obligatoriedad por parte de los patrones de una aportación para la } \\
\text { creación de fondos de vivienda para el trabajador. }\end{array}$ \\
\hline $\begin{array}{l}\text { INFONAVIT Casas } \\
\text { Grandes }\end{array}$ & 1980 & $\begin{array}{l}\text { En } 1972 \text { se crea el Instituto del Fondo Nacional de la Vivienda para los Trabajado- } \\
\text { res (INFONAVIT) con el objetivo de facilitar la adquisición de vivienda por parte } \\
\text { de trabajadores de bajos ingresos, a partir de la administración de aportaciones } \\
\text { obligatorias por parte de patrones. Durante esta primera etapa el Instituto estaba } \\
\text { a cargo de cada una de las fases de administración, diseño y construcción de los } \\
\text { conjuntos. }\end{array}$ \\
\hline $\begin{array}{l}\text { FOVISSSTE } \\
\text { Chamizal }\end{array}$ & 1980-1984 & $\begin{array}{l}\text { Promovido durante la primera etapa del Fondo de la Vivienda del Instituto de Se- } \\
\text { guridad y Servicios Sociales de los Trabajadores del Estado (FOVISSSTE) luego de } \\
\text { su creación en 1972; en } 1983 \text { se enmienda el artículo } 4 \text { constitucional, con lo cual el } \\
\text { derecho a la vivienda se convierte en un derecho reconocido por el estado mexica- } \\
\text { no y por consecuencia, una garantía de los individuos. }\end{array}$ \\
\hline $\begin{array}{l}\text { INFONAVIT } \\
\text { Solidaridad }\end{array}$ & $1990-1993$ & $\begin{array}{l}\text { Forma parte del cierre de la primera etapa del INFONAVIT y la transición en el } \\
\text { país a políticas públicas neoliberales; a partir de } 1992 \text { se consolidan reformas que } \\
\text { transforman a este organismo en una institución financiera. }\end{array}$ \\
\hline Eco 2000 & 1993 & $\begin{array}{l}\text { El Programa Nacional de Vivienda 1990-1994 establece el marco para que el sector } \\
\text { privado participe de manera activa en la construcción de vivienda de interés so- } \\
\text { cial, con lo cual el principal promotor de vivienda para trabajadores, el INFONAVIT, } \\
\text { se transforma en un ente financiero solamente. }\end{array}$ \\
\hline
\end{tabular}

Fuente: Maycotte y Sánchez, 2010. 


\section{Metodología}

En esta investigación se estudia la densificación como objeto general, tanto al nivel urbano-territorial como de los conjuntos de vivienda vertical de interés social. En la primera etapa de la investigación ya concluida se desarrolló un modelo de áreas aptas para densificación con uso habitacional a partir del planteamiento del "prisma de la sustentabilidad" (Berke et al., 2006), desde un enfoque de análisis espacial basado en sistemas de información geográfica (SIG), usando análisis multicriterio (AMC) y procesos de análisis jerárquico. El modelo integró una serie de datos geoespaciales que privilegian la existencia de condiciones de habitabilidad, equidad, oportunidad de desarrollo económico, respeto a la capacidad medioambiental y mitigación de riesgos (Sánchez y Rodríguez, 2017).

A partir del modelo de áreas aptas para la densificación, en este artículo presentamos un estudio que, en un primer momento se enfoca en el primer nivel, la escala urbano-territorial, realizando una superposición de los conjuntos de vivienda vertical analizados con el modelo integrado de áreas con aptitud para la densificación, así como con los sub-modelos que conforman el modelo integrado (medioambiente, economía, equidad y habitabilidad), que expresan la aptitud para la densificación desde esos factores. Así, fue posible identificar primero si estos desarrollos coinciden o no con áreas aptas para la densificación desde el punto de vista de la aptitud del suelo y detectar en qué medida coinciden con zonas de la ciudad que presentan niveles medios y altos en términos de equidad, habitabilidad, medioambientales y económicos.

El principal aporte del "prisma de la sustentabilidad" antes referido, es la inclusión del valor de "habitabilidad" a los tres valores clásicos de la sustentabilidad (medioambiente, economía, y equidad) -conocidos por su nombre en inglés como las tres E: Environment, Economy, Equity -con el propósito de integrar las necesidades y preferencias de los valores clásicos de la sustentabilidad (Berke et al., 2006). La opción por este posicionamiento deriva de la importancia de considerar la noción de habitabilidad como aspecto esencial del desarrollo sustentable, tanto a la escala territorial como del diseño urbano. Esto es de particular importancia cuando se estudia la densificación de conjuntos de vivienda vertical pues la habitabilidad es señalada como aspecto esencial que permite medir y/o promover el éxito de los desarrollos habitacionales densos (Sánchez, Maycotte, y Chávez, 2016), de hecho, encontraron bajos niveles de satisfacción de los residentes de los grandes desarrollos unifamiliares periféricos en Ciudad Juárez, ligados a las condiciones de habitabilidad tanto por las características precarias de la vivienda como por el contexto urbano en que se localiza, carente de 
servicios y alejado de satisfactores y redes familiares de soporte.

En la propuesta del The Smart Growth Manual se define: "Habitabilidad de barrio: El objetivo central de cualquier plan de crecimiento inteligente es la calidad de los barrios donde viven. Deben ser seguros, convenientes, atractivos y asequibles para todas las personas" (Duany, Speck y Lydon, 2010). Otras definiciones señalan la importancia de los aspectos del diseño urbano físico de las áreas habitacionales como medidas de habitabilidad:

La visión de las comunidades habitables constituye un campo importante para la planificación del desarrollo sostenible. La habitabilidad se enfoca en la creación de lugares cotidianos, que transforma el diseño de los espacios públicos (calles, aceras, parques) para alentar el compromiso de la comunidad; una combinación de tipos de edificios para mejorar la accesibilidad y dar cabida a una diversidad de actividades (Berke et al., 2006).

En el segundo nivel de estudio se realizó un análisis espacial y geoestadístico enfocado en los conjuntos de vivienda vertical y el análisis de los parámetros de densificación con que fueron proyectados. En particular, se contrastaron datos sobre densidad, tipologías y la cantidad de viviendas deshabitadas, con el propósito de comprender cómo se comporta la relación entre vivienda vertical y abandono de vivienda, que es un gran indicador del éxito o no de los desarrollos.

\section{Resultados}

\section{APTITUD PARA LA DENSIFICACIÓN Y UBICACIÓN DE DESARROLLOS DE VIVIENDA VERTICAL}

Para poder distinguir entre los aspectos urbanoterritoriales y de diseño urbano puntual, que puedan ser responsables de favorecer o no la sustentabilidad y habitabilidad de los conjuntos habitacionales, la primera fase del estudio de los principales conjuntos de vivienda vertical de interés social existentes en Ciudad Juárez fue dirigida por los siguientes cuestionamientos: ¿la ubicación de los conjuntos de vivienda vertical coincide con zonas aptas para la densificación, es decir, en suelos que cuentan con las capacidades urbanísticas para promover la densificación urbana? ¿Es importante que la ubicación favorezca que se cumplan criterios de habitabilidad, equidad, economía y medioambiente?

La superposición del modelo integrado de suelos aptos para la densificación con los conjuntos de vivienda vertical permitió verificar que en cuanto a la ubicación de los conjuntos, estos presentan mayor coincidencia en superficie con zonas aptas para la densificación en el siguiente orden: el INFONAVIT Casas Grandes (1980) con 78.92\% de coincidencia, el INFONAVIT Eco2000 (1992-93) con $74.70 \%$, el INFONAVIT Solidaridad (1990-93) 
con $61.87 \%$, el FOVISSSTE Chamizal (1980-84) con 52.47\%, el FOVISSSTE Burócrata (1956) con $39.77 \%$, y el FOVISSTE Sur (1975) con 29.66\% de coincidencia (Figura 1).

Las zonas aptas para la densificación expresan la integración de factores de habitabilidad, equidad, economía y medioambiente que favorecen las mejores condiciones para el desarrollo sustentables. En lo particular se caracterizan por

tener proximidad y accesibilidad a: rutas de transporte público, calles primarias y secundarias, paradas de autobuses e intersecciones, diferentes sistemas de movilidad, áreas de usos mixtos, distancias caminables a parques, espacios públicos verdes y abiertos; también cercanía a una mayor concentración de actividad urbana, servicios, comercio, áreas de mayor densidad de empleo, de valor medio del suelo, infraestructura, y equipamiento de salud, cultural, recreativo y de servicio, a las líneas principales de distribución de gas natural. (Sánchez y Rodríguez, 2017).

Además, también desde el punto de vista medioambiental, presentan mejores condiciones en términos de que

son áreas seguras y protegidas de riesgos, ya que evitan y se mantienen alejadas de: fallas geológicas, pendientes y áreas propensas a la erosión, arroyos intermitentes, áreas con mayor valor de suelo, derechos de vía para seguridad y protección de cuerpos de agua, llanuras inundables, drenajes pluviales, principales gas, alcantarillado y líneas eléctricas, rutas de carga, carreteras principales y zonas de pobreza (Sánchez y Rodríguez, 2017).

Buscando desarrollar un análisis más fino, se realizó la superposición de los conjuntos con tipologías de vivienda vertical con los sub-modelos de equidad, habitabilidad, economía y medioambiente, considerando niveles de aptitud alta y media para la densificación desde los cuatro factores (valores medios en el rango de 1 a 2 desviaciones estándar por encima de la media y valores altos superiores a 2 desviaciones estándar por encima de la media). Se buscó detectar cuáles de las variables que integran el modelo de zonas con potencial para densificación -habitabilidad, equidad, economía y medioambiente-, presentan menor o mayor coincidencia en superficie con los conjuntos habitacionales, reflejando por lo tanto, factores que en esas ubicaciones puedan estar disminuyendo las cualidades de sustentabilidad.

En términos generales, el análisis de sobreposición permitió detectar que, considerando los valores promedio de la suma de todos los porcentajes de hectáreas de coincidencia de los sub-modelos con los seis conjuntos con tipologías de vivienda vertical, el de equidad presenta el 96.74\%, el de economía el $80.9 \%$, y el de habitabilidad el $73.27 \%$, siendo el de medioambiente en el que las variables no muestran coincidencia con niveles altos y medios. Esto último se explica considerando que la aptitud para la densificación desde los factores del 
FIGURA 1. SUPERPOSICIÓN DEL MODELO INTEGRADO DE SUELOS APTOS PARA LA DENSIFICACIÓN CON LOS PRINCIPALES CONJUNTOS CON TIPOLOGÍAS DE VIVIENDA VERTICAL DE INTERÉS SOCIAL EXISTENTES EN CIUDAD JUÁREZ.

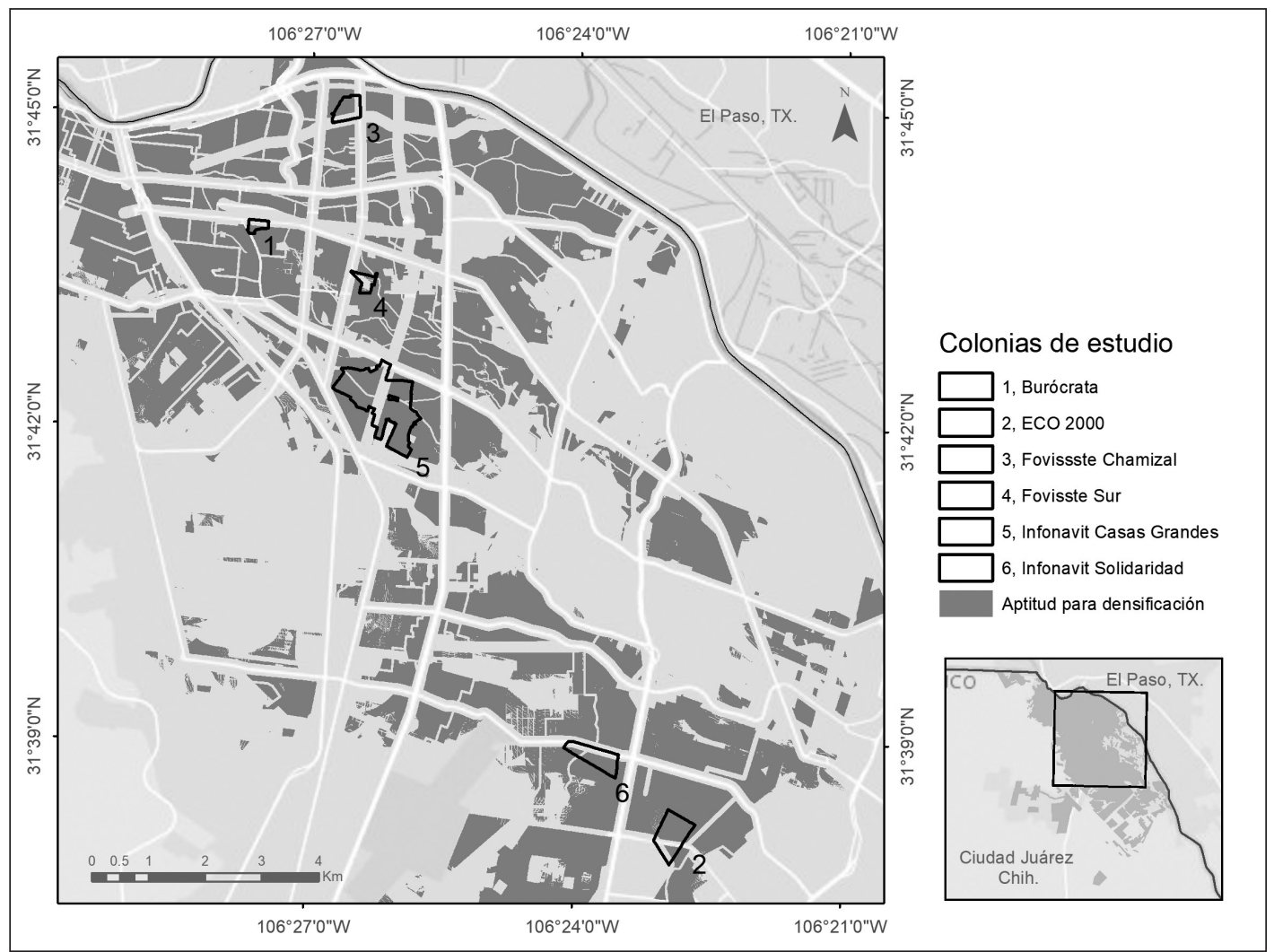

Fuente: elaboración propia, incluyendo modelo de Sánchez y Rodríguez (2017). 
sub-modelo medioambiental se valora en la medida en que se eviten o estén más alejados los riesgos, promoviendo la seguridad y protección de los desarrollos; de ahí que se presentan los "valores más altos hacia el margen urbano en las porciones suburbanas del área de estudio" (Sánchez y Rodríguez, 2017).

Analizando por separado los porcentajes de hectáreas de coincidencia de cada uno de los seis conjuntos con tipologías de vivienda vertical de interés social, se puede observar que existe un 100\% de coincidencia con niveles altos y medios de aptitud para la densificación desde el sub-modelo económico en el FOVISSSTE Burócrata (1956), el FOVISSSTE Chamizal (1980-84), el INFONAVIT Casas Grandes (1980) y el INFONAVIT Solidaridad (1990-93), seguidos por el INFONAVIT Eco2000 (1992-93) con 84.52\%, y quedando relegado en este aspecto el FOVISSTE Sur (1975) que presenta casi $1 \%$ de coincidencia. Esto se explica debido al hecho de que este desarrollo de vivienda se encuentra ubicado en una zona mayormente habitacional (Figura 2A). Así, a excepción del FOVISSSTE Sur, los demás conjuntos habitacionales están ubicados en zonas que favorecen el acceso a lugares de empleo, tanto comercial, de servicios como industrial.

En lo relativo a los factores de la habitabilidad se identificó mayor coincidencia en superficie con niveles altos y medios de aptitud para la densificación con el 100\% en INFONAVIT Eco2000 (1992-93), el $94.89 \%$ del FOVISSTE Sur (1975), el $84.02 \%$ del INFONAVIT Casas Grandes (1980), el 64.57 $\%$ del INFONAVIT Solidaridad (1990-93), el 52.47 $\%$ del FOVISSSTE Chamizal (1980-84) y el 43.67 $\%$ del FOVISSSTE Burócrata (1956) (Figura 2B). En este sub-modelo es necesario puntualizar que se integran solamente variables de la habitabilidad que pueden medirse desde el uso de datos geoestadísticos y espaciales. En concordancia con ello, los resultados expresan que los conjuntos estudiados cumplen en el porcentaje indicado arriba, con factores que favorecen la habitabilidad, entre los cuáles se encuentran el acceso a transporte público, a vialidades primarias y secundarias, ciclovías, distancias caminables a equipamientos públicos, parques y plazas, densidades poblacionales medias, la presencia de usos mixtos, y centros de barrio.

Por último, considerando los niveles altos y medios de aptitud para la densificación desde los factores de equidad, presentan mayor coincidencia en hectáreas el FOVISSTE Sur (1975) con 100\%, seguido por el FOVISSSTE Chamizal (1980-84) con $97.98 \%$, el INFONAVIT Casas Grandes (1980) con 97.71\%, el FOVISSSTE Burócrata (1956) con 96.1\%, el INFONAVIT Solidaridad (1990-93) con 94.71\%, el INFONAVIT Eco2000 (1992-93) con 93.95\% (Figura 2D). Esto significa que los conjuntos de vivienda vertical analizados cuentan a su alrededor con la mayoría de los servicios públicos y equipamientos básicos que garantizan equidad en acceso a educación, salud, recreación, cultura. 
FIGURA 2. SUPERPOSICIÓN DE LOS SUB-MODELOS CON NIVELES MEDIOS Y ALTOS DE APTITUD PARA LA DENSIFICACIÓN DESDE LOS FACTORES DE A) ECONOMÍA, B) HABITABILIDAD, C) MEDIO AMBIENTE Y D) EOUIDAD, CON LOS PRINCIPALES CONJUNTOS CON TIPOLOGÍAS DE VIVIENDA VERTICAL DE INTERÉS SOCIAL EXISTENTES EN CIUDAD JUÁREZ.

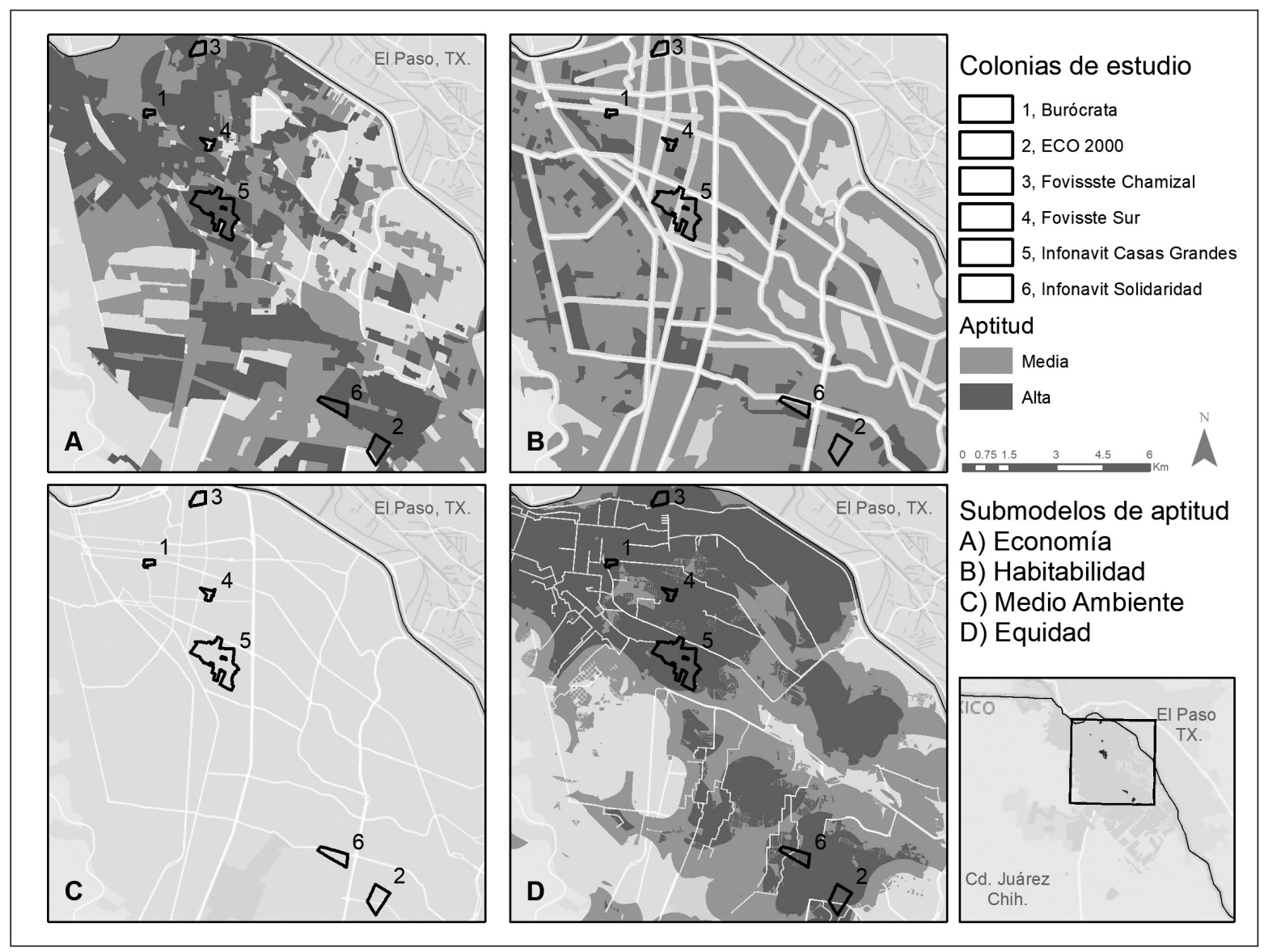

Fuente: elaboración propia, incluyendo modelo de Sánchez y Rodríguez, 2017. 
TABLA 2. PORCENTAJES DE COINCIDENCIA ENTRE NIVELES DE APTITUD PARA LA DENSIFICACIÓN Y LOS PRINCIPALES CONJUNTOS CON TIPOLOGÍAS DE VIVIENDA VERTICAL DE INTERÉS SOCIAL EN CIUDAD JUÁREZ.

\begin{tabular}{|c|c|c|c|c|}
\hline $\begin{array}{l}\text { Conjuntos con tipologías } \\
\text { de vivienda vertical de } \\
\text { interés social en } \\
\text { Ciudad Juárez }\end{array}$ & $\begin{array}{l}\text { Economía } \\
\text { Porcentaje de } \\
\text { coincidencia total } \\
\text { (Alto y Medio) }\end{array}$ & $\begin{array}{l}\text { Equidad } \\
\text { Porcentaje de } \\
\text { coincidencia total } \\
\text { (Alto y Medio) }\end{array}$ & $\begin{array}{l}\text { Habitabilidad } \\
\text { Porcentaje de } \\
\text { coincidencia total } \\
\text { (Alto y Medio) }\end{array}$ & $\begin{array}{l}\text { Promedio } \\
\text { Porcentaje de } \\
\text { coincidencia } \\
\text { (Alto y Medio) } \\
\text { Economía, } \\
\text { Equidad, y } \\
\text { Habitabilidad }\end{array}$ \\
\hline FOVISSSTE Burócrata 1956 & $100 \%$ & $96.10 \%$ & $43.67 \%$ & $79.92 \%$ \\
\hline FOVISSSTE Sur, 1975 & $0.96 \%$ & $100 \%$ & $94.89 \%$ & $65.29 \%$ \\
\hline $\begin{array}{l}\text { FOVISSSTE Chamizal, } \\
\text { 1980-84 }\end{array}$ & $100 \%$ & $97.98 \%$ & $52.47 \%$ & $83.48 \%$ \\
\hline $\begin{array}{l}\text { INFONAVIT Casas Gran- } \\
\text { des, 1980s }\end{array}$ & $99.94 \%$ & $97.71 \%$ & $84.02 \%$ & $93.89 \%$ \\
\hline ECO 2000, 1990-92 & $84.52 \%$ & $93.95 \%$ & $100 \%$ & $92.82 \%$ \\
\hline $\begin{array}{l}\text { INFONAVIT Solidaridad, } \\
\text { 1990-93 }\end{array}$ & $100 \%$ & $94.71 \%$ & $64.57 \%$ & $86.42 \%$ \\
\hline
\end{tabular}

Fuente: Elaboración propia con base en datos del modelo de Sánchez y Rodríguez, 2017.

Recapitulando, y observando ahora desde los conjuntos habitacionales con tipologías de vivienda vertical, en términos del promedio de la sumatoria de coincidencia en hectárea con los sub-modelos de economía, habitabilidad y equidad se encontró que presentan mayores porcentajes el INFONAVIT Casas Grandes (1980) con 93.89\%, seguido por el INFONAVIT Eco2000 (1992-93) con 92.82\%, el INFONAVIT Solidaridad (1990-93) con 86.42\%, el FOVISSSTE Chamizal (1980-84) con $83.48 \%$, el FOVISSSTE Burócrata (1956) con 79.92\% y el FOVISSTE Sur (1975) con 65.29\% (Tabla 2). En términos de equidad todos los conjuntos presentan porcentajes arriba del $90 \%$ y con relación a las variables económicas todos superan el 84\%, a excepción del FOVISSSTE Sur que curiosamente, presenta menos de $1 \%$ de coincidencia con niveles medios y altos, pero uno de los porcentajes más 
altos en términos de los niveles medios y altos de habitabilidad. Sin embargo, en términos de habitabilidad los resultados son más bajos en general y se observan más diferencias en rangos, quedando por debajo del $84 \%$ cuatro de los seis conjuntos, siendo el FOVISSSTE Burócrata y el FOVISSSTE Chamizal los que alcanzan menores valores.

\section{CONJUNTOS CON VIVIENDA VERTICAL: TIPOLOGÍAS Y VIVIENDA DESHABITADA}

Por último, en un segundo nivel, nos enfocamos en el análisis espacial y geoestadístico de los parámetros de densidad bruta de los conjuntos con tipologías de vivienda vertical y los porcentajes de vivienda deshabitada en cada uno, a partir de la información oficial disponible en el último Censo de Población y Vivienda (Instituto Nacional de Estadística y Geografía [INEGI], 2010). El nivel de vivienda deshabitada es indicativo de la habitabilidad del desarrollo, por lo cual reviste especial importancia como criterio para evaluar el éxito de los planteamientos de densidad y tipología de los conjuntos habitacionales.

Contrastando el tamaño de las superficies totales de los conjuntos y la cantidad de vivienda, se verificó que los seis conjuntos presentan densidades brutas en el rango de 40 a 60 viviendas por hectárea. En términos de la cantidad de vivienda deshabitada, se presentan mayores porcentajes en el siguiente orden: el FOVISSSTE Burócrata (1956) presenta 69 viviendas deshabitadas del total de 199, lo que representa un 34.7\% del total de viviendas del conjunto; ECO 2000 (1990-93) cuenta con 263 viviendas deshabitadas del total de 1,018 viviendas, llegando a un 25.8\%; sigue el FOVISSSTE Chamizal (1980-84), donde se señalan 204 viviendas deshabitadas del total de 989 viviendas, lo que representa un 20.6\% del total; el INFONAVIT Solidaridad presenta 246 viviendas deshabitadas de un total de 1,289 viviendas, llegando a un $19.1 \%$ de abandono. Los menores índices de vivienda deshabitada se presentan en el INFONAVIT Casas Grandes (1980s) con un 13.7 $\%$ de abandono, relativo a 603 viviendas abandonadas del total de 4,400. El valor más bajo se presenta en el FOVISSTE Sur (1975) con un $8.8 \%$ que representan sus 43 viviendas deshabitadas del total de 488 (Tabla 3).

Considerando el porcentaje de viviendas deshabitadas y el porcentaje de coincidencia espacial con niveles medios y altos de habitabilidad, es posible verificar en dos casos que, a niveles altos de vivienda deshabitada corresponden porcentajes bajos de coincidencia con áreas de nivel medio y alto de habitabilidad. Esto es así en el caso del FOVISSSTE Burócrata (1956) y el FOVISSSTE Chamizal (198084) con $43.7 \%$ y $52.5 \%$ de coincidencia con niveles altos y medios de habitabilidad (Tabla 2). Es también posible observar en otros dos casos que, a niveles bajos de vivienda deshabitada corresponden 


\section{TABLA 3. PORCENTAJES DE VIVIENDA DESHABITADA EN LOS PRINCIPALES CONJUNTOS CON TIPOLOGÍAS DE VIVIENDA VERTICAL DE INTERÉS SOCIAL EXISTENTES EN CIUDAD JUÁREZ.}

\begin{tabular}{lllll|}
$\begin{array}{l}\text { Conjuntos con tipologías de vivienda } \\
\text { vertical }\end{array}$ & Población (hab.) & Total de viviendas & $\begin{array}{l}\text { Vivienda en } \\
\text { abandono }\end{array}$ & $\begin{array}{l}\text { Porcentaje de } \\
\text { vivienda en } \\
\text { abandono }\end{array}$ \\
\hline FOVISSSTE Burócrata, 1956 & 393 & 199 & 69 & $34.7 \%$ \\
\hline INFONAVIT ECO 2000, 1990-92 & 2,810 & 1,018 & 263 & $25.8 \%$ \\
\hline FOVISSSTE Chamizal, 1980-84 & 2,331 & 989 & 204 & $20.6 \%$ \\
\hline INFONAVIT Solidaridad, 1990-93 & 4,066 & 1,289 & 246 & $19.1 \%$ \\
\hline INFONAVIT Casas Grandes, 1980 & 12,334 & 4,400 & 603 & $13.7 \%$ \\
\hline FOVISSSTE Sur, 1975 & 1,302 & 488 & 43 & $8.8 \%$ \\
\hline
\end{tabular}

Fuente: elaboración propia (autor), incluyendo datos de INEGI (2010)

porcentajes altos de coincidencia con áreas de nivel medio y alto de habitabilidad, tal es el caso de el FOVISSTE Sur (1975) y el INFONAVIT Casas Grandes (1980). Solo en el caso de Eco2000 se presentó un alto porcentaje de vivienda deshabitada, de $25.8 \%$, y $100 \%$ de coincidencia con los factores de habitabilidad contemplados en la modelación. Esto deja en evidencia que aún en ubicaciones que cuentan con factores que favorecen la habitabilidad pueden presentarse aspectos relativos al diseño de los conjuntos y las tipologías que pueden provocar el fracaso de los desarrollos densos, desde el punto de vista de los aspectos de la habitabilidad, expresada desde la vivienda deshabitada

Como último paso, analizamos la vivienda deshabitada al nivel de manzanas, entendidas como los polígonos rodeados de calles, no siempre rectangulares, que conforman las unidades básicas de la estructura urbana. Esto nos permitió identificar que los porcentajes de vivienda deshabitada no se comportan de modo homogéneo en los conjuntos, sino que los valores más altos están concentrados en algunas manzanas, y muchas de ellas coinciden con ubicaciones próximas a los perímetros exteriores de los conjuntos, sus áreas menos accesibles y las tipologías en vertical. En el caso del FOVISSSTE Burócrata (1956), el conjunto presenta edificios plurifamiliares de cuatro y más niveles y vivienda unifamiliar; sin embargo, la forma en que se presentan los datos estadísticos no permitió dividir el conjunto en manzanas y en este caso todo el conjunto expresa valores de $34.7 \%$ de vivienda deshabitada (Figura 3). 
FIGURA 3. FOVISSSTE BURÓCRATA. PORCENTAJE DE VIVIENDA DESHABITADA POR MANZANAS.

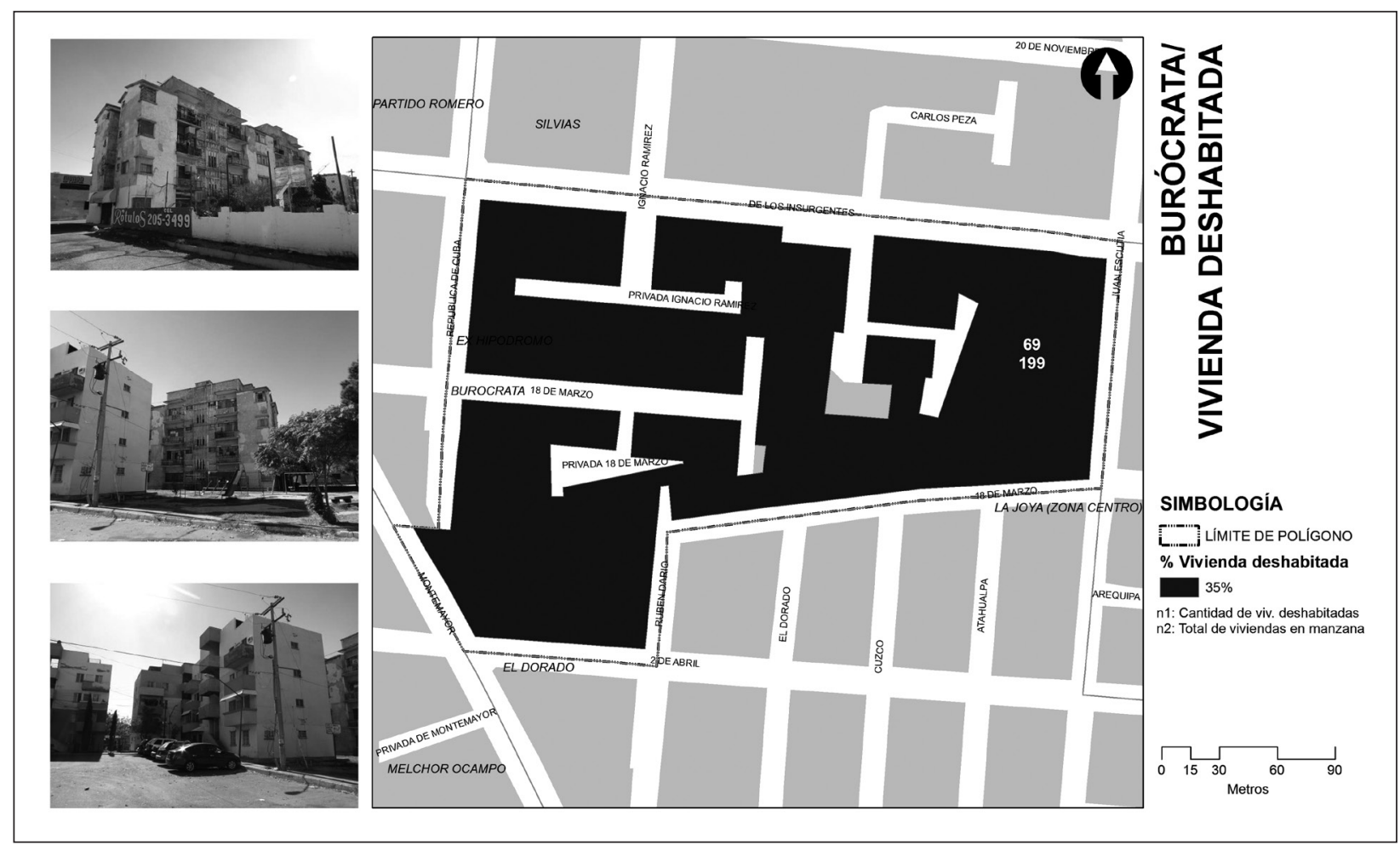

Fuente: elaboración propia, incluyendo datos de INEGI (2010). 
FIGURA 4. FOVISSSTE SUR PORCENTAJE DE VIVIENDA DESHABITADA POR MANZANAS.

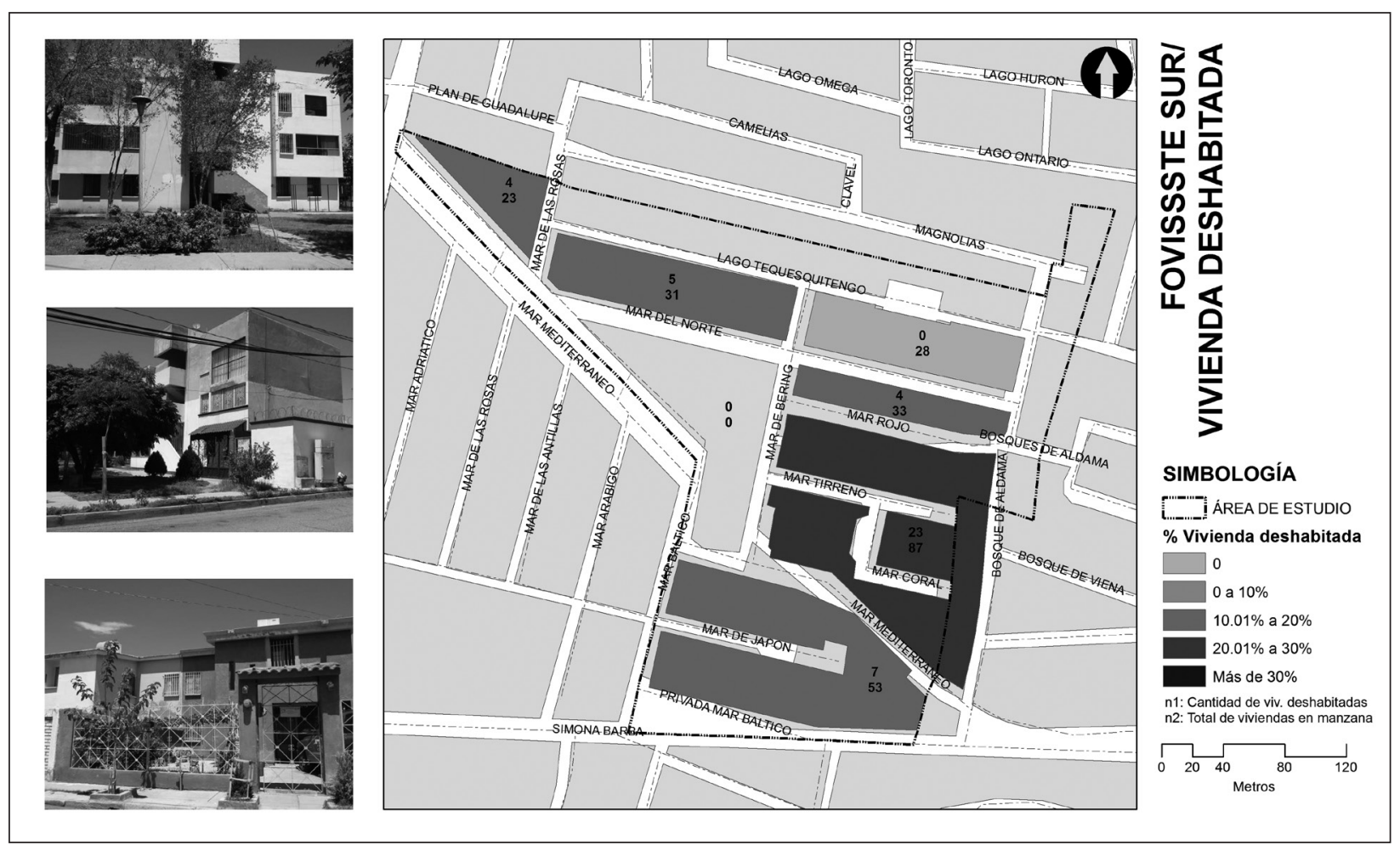

Fuente: elaboración propia, incluyendo datos de INEGI (2010). 
En el caso del FOVISSSTE Sur, está conformado por siete manzanas, siendo una área de parque y seis con vivienda construida, presentándose tres tipologías: unifamiliar, vivienda vertical y combinado (unifamiliar y plurifamiliar en una misma manzana). Del total de seis manzanas, ninguna presenta porcentajes de vivienda deshabitada de más de 30\%, solo una manzana presenta de 20 a 30\% (Figura 4), siendo relevante observar que dicha manzana presenta tipologías combinadas. Del resto de las manzanas, una presenta tipologías de vivienda vertical con rango de 10 a 20\% de vivienda deshabitada y otras cuatro presentan tipologías de vivienda unifamiliar, de las cuales tres presentan un rango de 10 a 20\% y solo una de las manzanas no presenta vivienda deshabitada.

El FOVISSSTE Chamizal presenta un total de 24 manzanas, de las cuales ocho con tipologías de vivienda vertical, 10 combinadas de vivienda vertical y unifamiliar y seis de vivienda unifamiliar. Del total de las 24 manzanas, solo tres presentan más de 30\% de vivienda deshabitada, dos presentan tipologías de vivienda vertical y una manzana presenta tipologías combinadas (Figura 5). Por otro lado, del total de siete manzanas que presentan entre 20 y $30 \%$ de vivienda deshabitada, dos coinciden con tipologías de vivienda vertical, cuatro presentan tipologías combinadas y una manzana con unifamiliar, siendo necesario aclarar que esta se encuentra rodeada en su totalidad por tipologías combinadas. Analizando las 10 manzanas que presentan porcentajes de vivienda deshabitada entre 10 y $20 \%$, tres manzanas presentan tipologías de vivienda vertical, cuatro presentan tipologías combinadas y tres manzanas presentan unifamiliares. En el caso de las manzanas con ninguna vivienda deshabitada se presentan cuatro manzanas en total, de las cuales, una manzana presenta tipologías de vivienda vertical, una tipologías combinadas y dos tipologías unifamiliares.

En el caso de Eco 2000, de las 25 manzanas que pudimos analizar $^{6}, 18$ presentan tipologías de vivienda vertical, cinco combinadas de vivienda vertical y unifamiliar y dos de vivienda unifamiliar. A diferencia de los dos conjuntos anteriores, en este se presentan cinco manzanas con porcentajes de vivienda deshabitada aún mayores de 40 a

6 En este nivel de análisis fue necesario hacer un recorte del área de estudio de Eco 2000 debido a dos razones: 1) los datos estadísticos unían manzanas del conjunto con otros barrios vecinos y 2) el conjunto está dividido en etapa 1 y 2 , y en la actualidad en la etapa 2 se presenta un fenómeno de ocupación ilegal de vivienda, y a raíz de estos factores, excluimos los sectores afectados por estas condiciones, pues no serían confiables los datos de abandono. 
FIGURA 5. FOVISSSTE CHAMIZAL. PORCENTAJE DE VIVIENDA DESHABITADA POR MANZANAS.

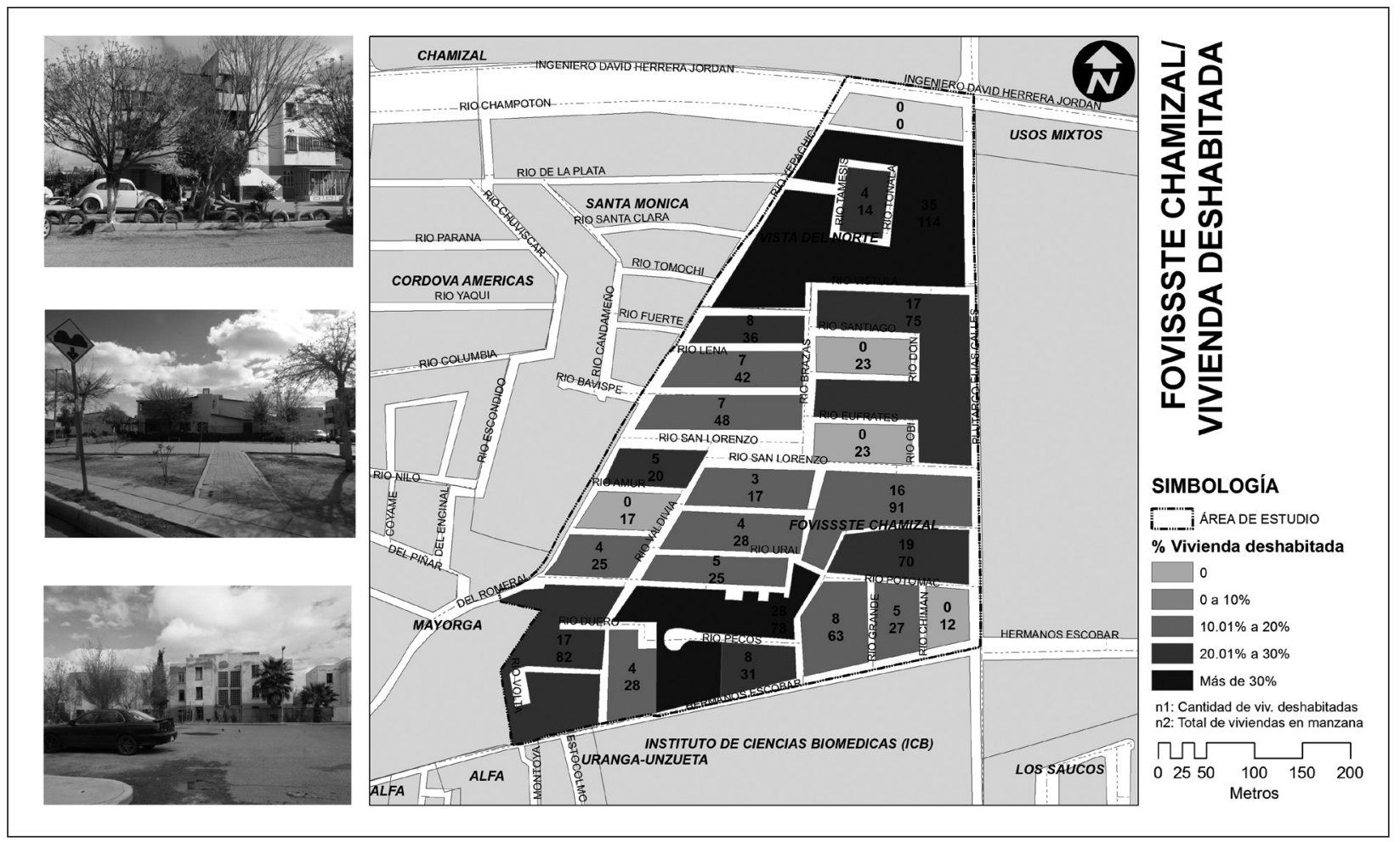

Fuente: elaboración propia, incluyendo datos de INEGI (2010). 
$50 \%$, de los cuales cuatro presentan tipologías de vivienda vertical, y una de unifamiliar. Además de ello, nueve manzanas presentan más de 30\% de vivienda deshabitada, de las cuales siete presentan tipologías de vivienda vertical y dos manzanas presentan tipologías combinada (Figura 6). Entre 20 y 30\% de vivienda deshabitada se encuentran cinco manzanas, de las cuales dos coinciden con tipologías de vivienda vertical y tres presentan tipologías combinadas. Contamos cinco manzanas que presentan porcentajes de vivienda deshabitada entre 10 y $20 \%$, coincidiendo las cinco manzanas con tipologías de vivienda vertical. Solo se presenta una manzana de tipología unifamiliar sin vivienda deshabitada.

En el INFONAVIT Solidaridad, aunque se extiende por 27.5 hectáreas, la forma en que fue planteado el diseño urbano con continuidad entre las manzanas provoca que a nivel de los datos estadísticos solo puedan discernirse siete manzanas. Un aspecto positivo en este conjunto es que ninguna de las manzanas presenta niveles de vivienda deshabitada de 30\% (Figura 7). Cuatro manzanas con tipologías de vivienda vertical presentan de 20 a $30 \%$ de vivienda deshabitada y una con niveles de menos de $10 \%$. Las dos grandes manzanas que se identifican con tipologías combinadas presentan de 10 a 20\% de vivienda deshabitada.

En suma, considerando todos los conjuntos que pudieron ser analizados en detalle a nivel de manzana en esta sección ${ }^{7}$, de las 32 manzanas ocupadas con tipologías de vivienda vertical, apenas dos manzanas presentan niveles de abandono de menos del $10 \%$, presentándose un $65.6 \%$ de vivienda deshabitada entre 20 y 50\% (Tabla 3). En el caso de las manzanas ocupadas con tipologías combinadas de vivienda vertical y unifamiliar, una cuenta con niveles de abandono de menos del 10\%, y el 61\% de las manzanas presentan niveles de abandono entre 20 y $40 \%$, siendo relevante mencionar que no se presentan valores por encima de $40 \%$. Con relación a las manzanas ocupadas con tipologías unifamiliares, en su mayoría de dos niveles, de las 12 manzanas presentes en los conjuntos analizados el 33.3\% presenta bajos niveles de abandono de 0 a $10 \%$, y el $58.3 \%$ de las manzanas presenta entre 20 y $30 \%$ de vivienda deshabitada.

7 EI INFONAVIT Casas Grandes no se detalló por manzana debido a que sus 116.1 hectáreas hacen muy extenso el estudio y no se consideró relevante ya que cuenta con tipologías similares a los demás. 
FIGURA 6. INFONAVIT ECO 2000. PORCENTAJE DE VIVIENDA DESHABITADA POR MANZANAS.

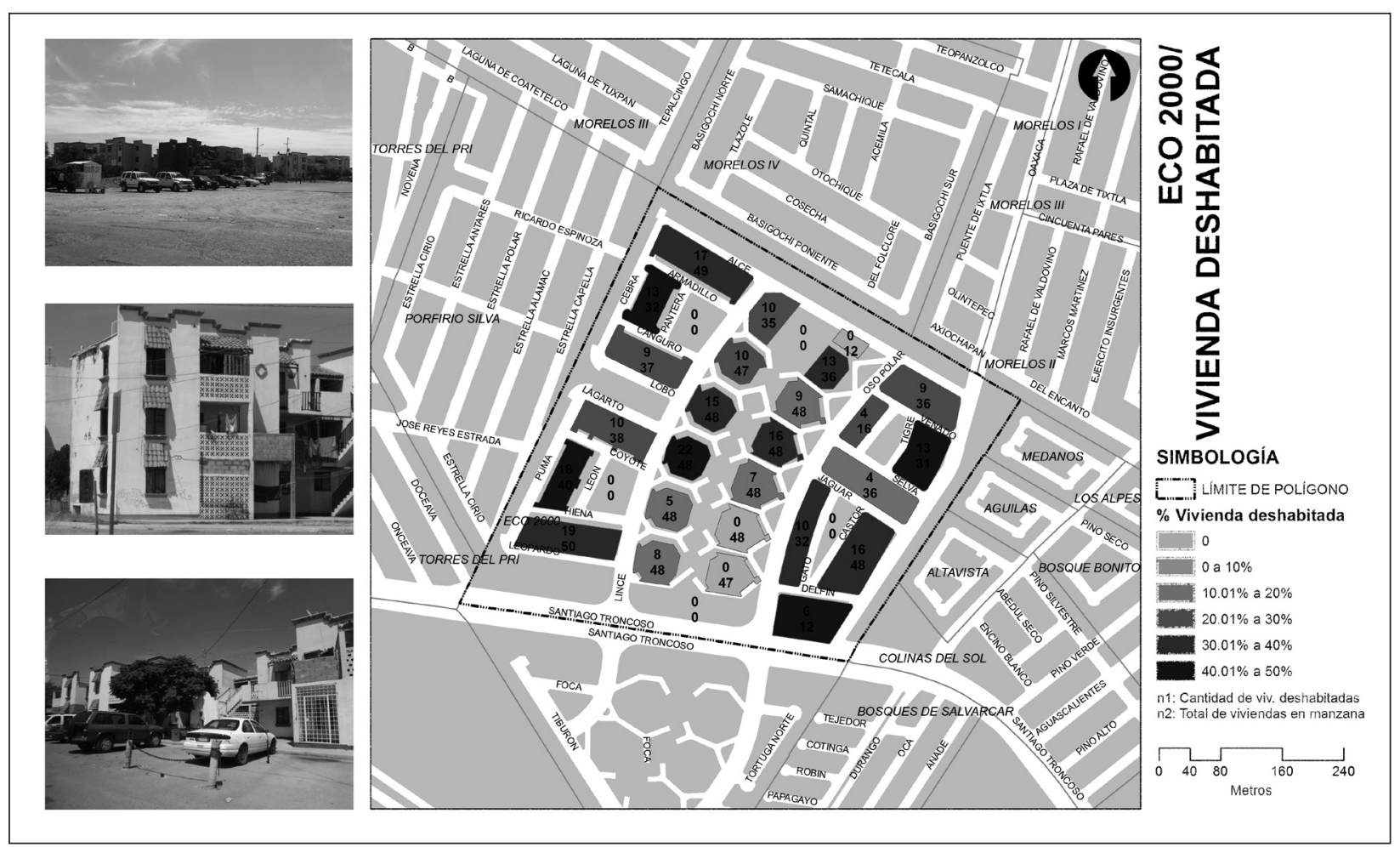

Fuente: elaboración propia, incluyendo datos de INEGI (2010). 
FIGURA 7. INFONAVIT SOLIDARIDAD. PORCENTAJE DE VIVIENDA DESHABITADA POR MANZANAS.

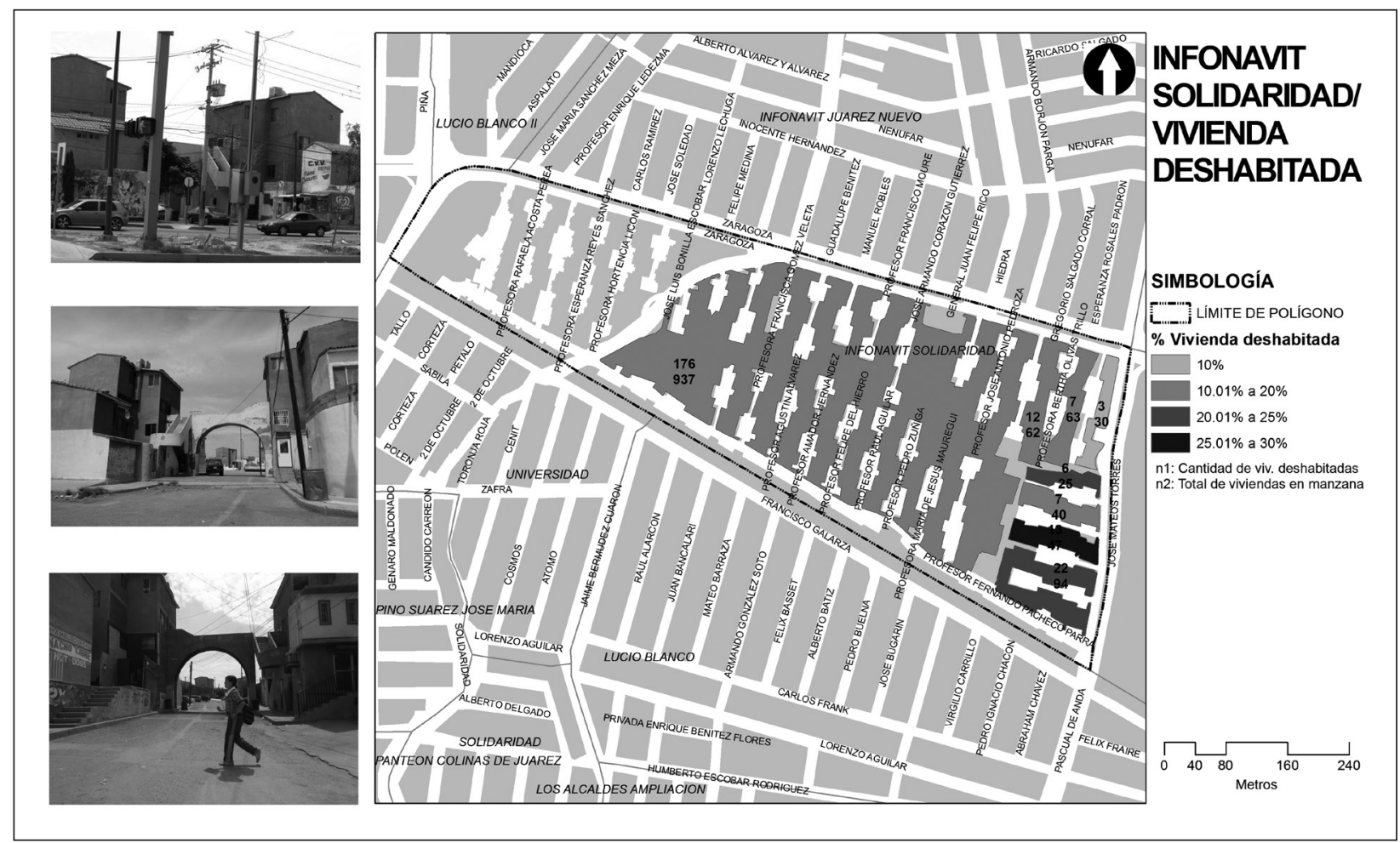

Fuente: elaboración propia, incluyendo datos de INEGI (2010). 


\section{TABLA 4. RANGOS DE VIVIENDA DESHABITADA POR TIPOLOGÍAS EN LOS PRINCIPALES CONJUNTOS CON TIPOLOGÍAS DE VIVIENDA VERTICAL DE INTERÉS SOCIAL EXISTENTES EN CIUDAD JUÁREZ.}

\begin{tabular}{|c|c|c|c|c|c|c|c|c|c|c|c|}
\hline TIPOLOGÍA & $\begin{array}{c}\text { \# } \\
\text { manzanas }\end{array}$ & & $\begin{array}{l}50 \% \\
\text { enda } \\
\text { labit. }\end{array}$ & & $\begin{array}{l}40 \% \\
\text { enda } \\
\text { habit. }\end{array}$ & & $\begin{array}{c}30 \% \\
\text { enda } \\
\text { nabit. }\end{array}$ & & $\begin{array}{l}20 \% \\
\text { enda } \\
\text { labit. }\end{array}$ & & $\begin{array}{l}10 \% \\
\text { enda } \\
\text { enabit. }\end{array}$ \\
\hline Vivienda vertical & 32 & 4 & $12.5 \%$ & 9 & $28.1 \%$ & 8 & $25 \%$ & 9 & $28.1 \%$ & 2 & $6.3 \%$ \\
\hline $\begin{array}{l}\text { Combinada (verti- } \\
\text { cal y unifamiliar) }\end{array}$ & 18 & 0 & $0 \%$ & 3 & $16.6 \%$ & 8 & $44.5 \%$ & 6 & $33.3 \%$ & 1 & $5.6 \%$ \\
\hline Unifamiliar & 12 & 1 & $8.3 \%$ & 0 & $0 \%$ & 1 & $8.3 \%$ & 6 & $50 \%$ & 4 & $33.4 \%$ \\
\hline
\end{tabular}

Fuente: Elaboración propia, incluyendo datos de INEGI (2010).

\section{Conclusiones}

Considerando que la política actual otorga subsidios no solo para la adquisición de una vivienda nueva, sino de una vivienda usada, es necesario observar el potencial que se encuentra en estos conjuntos que tienen alta coincidencia con los suelos aptos para la densificación y donde existen un total de 1428 viviendas deshabitadas. Desde el objetivo e intención del estudio, de presentar estrategias y criterios, tanto desde la ubicación como del diseño del conjunto, que permitan que los desarrollos densos puedan dar lugar a comunidades más sustentables y habitables, una primera reflexión se enfoca en el potencial de los conjuntos analizados y lo que debería hacerse, en términos de inversión pública municipal, para mejorar sus condiciones y favorecer la inserción y permanencia de la población en ellos mismos.

En los seis conjuntos analizados, el factor habitabilidad es el menos consistente, es decir, el que presenta menor porcentaje de niveles altos y medios coincidiendo con la superficie de los conjuntos, y se presenta acompañado de altos porcentajes de vivienda deshabitada, en su mayoría en manzanas con tipologías de vivienda vertical en su totalidad o combinadas. Esto es especialmente importante, 
en el orden que sigue, en el FOVISSSTE Burócrata (1956), el INFONAVIT Eco2000, el FOVISSSTE Chamizal (1980-84), en el INFONAVIT Solidaridad (1990-93) y en el caso del INFONAVIT Casas Grandes (1980). El estudio demuestra que es necesario mejorar los factores que inciden en mayores índices de habitabilidad, es decir, que mejoran la interacción, la seguridad y el arraigo de los habitantes. Entre estos pueden estar mejorar el acceso de las rutas de transporte público; actualizar vialidades considerando cruces seguros y ciclovías que permitan la movilidad alternativa; mejorar la calidad de los parques y espacios públicos que se encuentran a distancias caminables. Además, considerando que son las tipologías de vivienda vertical en su totalidad o combinadas las que presentan mayores porcentajes de abandono, y que han recibido poco mantenimiento porque su altura dificulta las posibilidades de intervención directa por parte de los habitantes, se evidencia que es necesario trabajar a nivel municipal y con la comunidad para crear esquemas de mantenimiento de las edificaciones. Estos esquemas deberían garantizar que la ciudad esté preparada para ofrecer la vivienda vertical como una opción viable social y económicamente de vivienda de interés social, garantizando condiciones de seguridad y protección civil.

Recapitulando, el FOVISSSTE Burócrata (1956) cuenta con 69 viviendas deshabitadas, el 34.7\% del total, en su mayoría en los edificios plurifamiliares que ya tienen más de 60 años, y coincide solo en un $43.67 \%$ de su superficie con suelos aptos para la densificación desde el factor habitabilidad.

El INFONAVIT Eco2000 (1992-93) cuenta con 263 viviendas deshabitadas, un 25.8\% del total, aunque coincide en $100 \%$ con suelos con potencial para la densificación desde el factor habitabilidad. Lo que evidencia que, a pesar de que su ubicación presenta condiciones muy favorables para la habitabilidad -asociados en mayor medida a la presencia de transporte público y acceso a vialidades primarias y secundarias-; el diseño del conjunto puede promover o no la habitabilidad. Este fue el único conjunto donde se observaron manzanas con porcentajes de vivienda deshabitada de más de 40\%; y las 18 manzanas con tipologías de vivienda vertical y combinadas presentan entre 20 y $40 \%$ de vivienda deshabitada. De modo que, al igual que en el caso anterior, la situación que presentan las tipologías en vertical exigen que se organicen estructuras y esquemas comunitarios que promuevan el mantenimiento de los edificios y la protección de los habitantes.

El FOVISSSTE Chamizal (1980-84) cuenta con 204 viviendas deshabitadas y coincide solo en un $52.47 \%$ de su superficie con niveles altos y medios de aptitud para la densificación desde el factor habitabilidad. En ese sentido, considerando que las viviendas deshabitadas representan el 20.6\% del total y que del total de 24 manzanas, 17 presentan 
tipologías de vivienda vertical en su totalidad o combinadas con niveles de abandono entre $10 \mathrm{y}$ 40\%; es necesario mejorar la habitabilidad del conjunto, en particular de las sectores con vivienda vertical.

El INFONAVIT Solidaridad (1990-93) cuenta con 246 viviendas deshabitadas, $19.1 \%$ del total, y su superficie coincide con suelos aptos para la densificación desde el factor habitabilidad en un $64.57 \%$; siendo que, de las siete manzanas analizadas cuatro presentan tipologías de vivienda vertical en su totalidad o combinadas con niveles de abandono entre 20 a $30 \%$.

En el caso del INFONAVIT Casas Grandes (1980) se presentan 603 viviendas deshabitadas, 13.7\% del total, y coincide un $52.47 \%$ de su superficie con suelos con niveles altos y medios de aptitud para la densificación desde el factor habitabilidad. En ese sentido, una estrategia que favorecería la sustentabilidad, sería atender los factores de la variable habitabilidad buscando detener el abandono de vivienda y promover un desarrollo más vibrante y habitable de la comunidad.

El FOVISSTE Sur (1975) fue el único que coincidió en $94.89 \%$ altos niveles de aptitud para la densificación desde los factores de habitabilidad, y solo a 8.8\% de vivienda deshabitada, 43 unidades. El aspecto de economía es el que presenta niveles muy bajos, pero en este caso es importante mencionar que el conjunto está directamente conectado con la Av. Adolfo López Mateos, que da acceso a una gran cantidad de zonas de concentración de actividad urbana de servicios y comercio; por lo que considerando que tiene más de 40 años de edificado, puede ser necesario una revisión del uso de suelo a fin de permitir actividades comerciales de barrio en las zonas alrededor de plazas y parques, que dinamicen más la economía comunitaria, y al mismo tiempo otorguen más intensidad de uso a los espacios abiertos.

Como último punto de estas reflexiones finales, podemos ahora responder una de las preguntas que nos planteamos al inicio: ies importante que la ubicación favorezca que se cumplan criterios de habitabilidad, equidad, economía y medioambiente? Es válido afirmar que la respuesta a esta interrogante es un claro sí, considerando que el análisis de estos conjuntos habitacionales permitió validar la asertividad del modelo de potencial de densificación, pues fue posible identificar los factores que están incidiendo en mayor o menor medida en la capacidad de ofrecer condiciones de sustentabilidad tanto por ubicación como por tipologías y que favorecen o no la posibilidad de hacer comunidades habitables y sustentables. El estudio permitió verificar que, para plantear una propuesta de densificación sustentable es necesario no solamente considerar aspectos urbano-territoriales como la identificación de suelos aptos para la densificación, sino que además, hay que prestar especial atención a las cualidades del diseño y 
planteamiento urbano del conjunto, que permitan sentar bases sólidas para una densificación equilibrada y sustentable. De modo que el éxito o no de estos conjuntos dependerá tanto de su ubicación en la ciudad, como del diseño de los mismos.

Con relación a este último aspecto, consideramos que, además de respetar el ubicar los desarrollos densos en los suelos que cuentan con la aptitud urbanística para ello, es importante evitar conjuntos habitacionales masivos de más de ocho hectáreas que crean grandes murallas urbanas, barreras sociales y promueven la falta de pluralidad y diversidad. Es necesaria una distribución más equilibrada del espacio libre dedicado a parques y jardines, las vialidades y estacionamientos deben reducirse a porcentajes mínimos y encontrar soluciones sustentables y flexibles; la introducción de tipologías de vivienda vertical debe acompañarse de una estructura organizativa que favorezca el cuidado y mantenimiento. En suma, es necesario prestar mayor atención al espacio dedicado a las personas, que al de los autos, tanto al nivel de las tipologías arquitectónicas, como de la cantidad y calidad de los espacios verdes y abiertos.

\section{Referencias bibliográficas}

Berke, P.R., Godschalk, D.R., Kaiser, E.J., y Rodríguez, D.A. (2006). Urban land use planning (5a. ed.). Chicago: University of Illinois Press.

Duany, A., Speck, J., y Lydon, M. (2010). The smart growth manual. New York: McGraw Hill.

Hagan, S. (2015). Ecological urbanism: the nature of the city. Londres: Taylor \& Francis.

INEGI. (2010). Censo de población vivienda. Aguascalientes, AGS, México: Instituto Nacional de Estadística y Geografía.

Le Corbusier. (2009). Urbanismo. São Paulo: WMF Martins Fontes.

Marsh, W.M. y Grossa, J.M. (1996). Environmental geography. Science, land use, and earth systems (3a. ed.). New York: Wiley.

Maycotte, E. y Sánchez, E. (2010). Ciudades dispersas, viviendas abandonadas: La política de vivienda y su impacto territorial y social en las ciudades mexicanas. ACE: Architecture, city and environment, 5(14), 19-32. https://doi.org/10.5821/ace. v5il4.2503

Mumford, E. (2002). The CIAM discourses on urbanism, 1928-1960. Cambridge, Massachusetts: The MIT Press.

Reglas de operación del programa de acceso al financiamiento para soluciones habitacionales, del ejercicio fiscal 2016. (2015). Diario Oficial de la Federación, 29 de diciembre de 2015. 
Rodríguez, M., Morales, S., y Curiel, M. (2015). Áreas centrales (des)habitadas en Ciudad Juárez: densidad habitacional, seguridad urbana y uso del espacio público. En A. González y M. Rodríguez, Patrimonio arquitectónico y urbano. Paisaje cultural y diseño urbano (pp. 85-100). Ciudad Juárez: Universidad Autónoma de Ciudad Juárez.

Sánchez, E., Maycotte, E., y Chávez, J. (2016). Spatial patterns of social mobility perception derived from access to social housing in a Mexican border city. Proceedings International Congress Virtual Cities and Territories, Barcelona, 11, 1326-1345.

Sánchez, E. y Rodríguez, M. (2017). Spatial suitability for urban sustainable densification in a borderland city. Journal of Geography and Regional Planning, 10(10), 266-277. https://doi.org/10.5897/ JGRP2017.0648 